\title{
Multispecies aggregations of mushroom corals in the Gambier Islands, French Polynesia
}
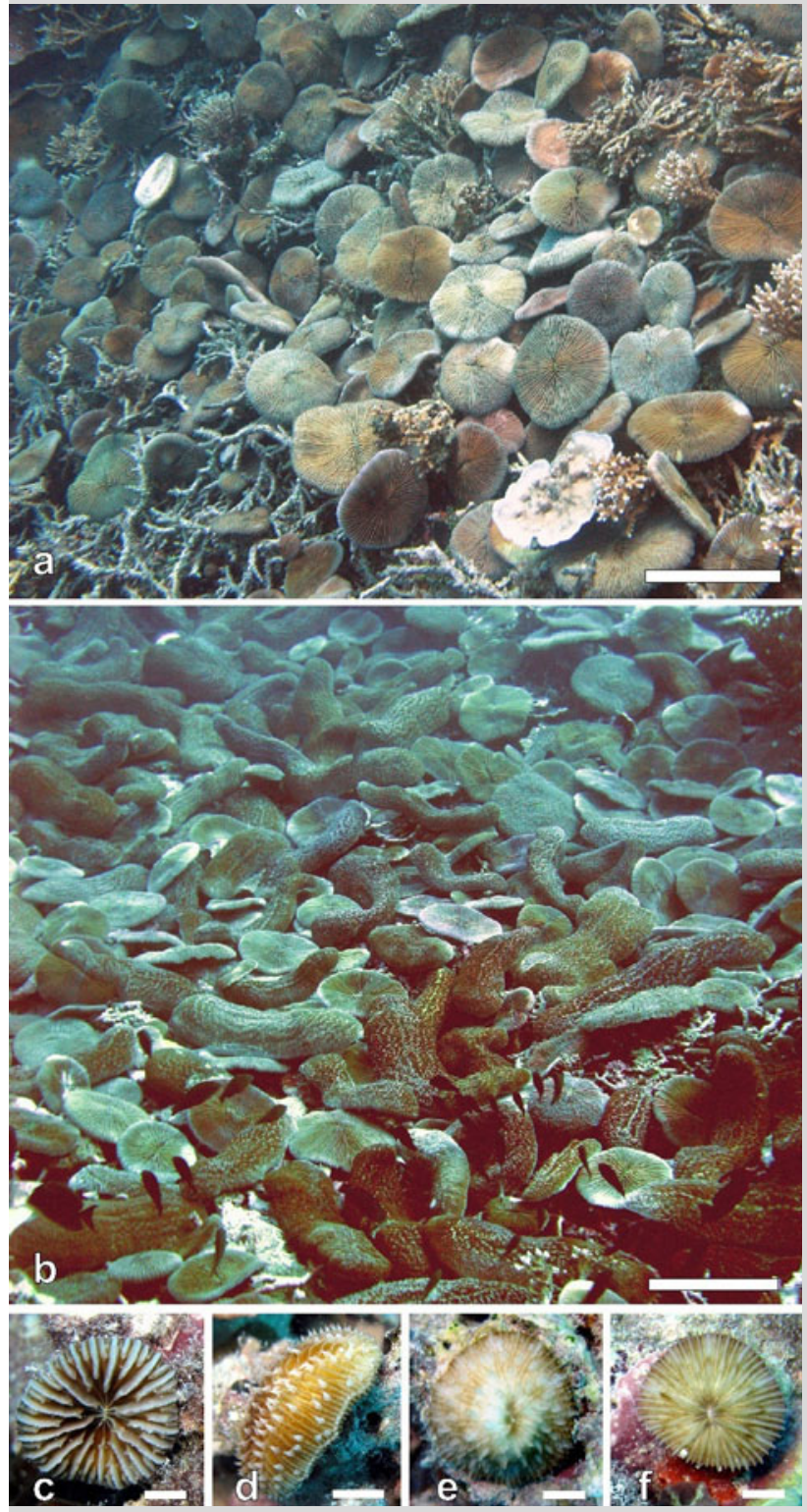

Fig. 1 Multispecies mushroom coral aggregations in two depth zones on a lagoon pinnacle at Mangareva Island, Gambier Islands: a $5 \mathrm{~m}$, b $20 \mathrm{~m}$. Scale bars $20 \mathrm{~cm}$. Attached juveniles: c Danafungia scruposa, d Herpolitha limax, e Lobactis scutaria, $\mathbf{f}$ Lithophyllon repanda. Scale bars $1 \mathrm{~cm}$
The coral reefs of the isolated Gambier Islands were studied mid-2011 at 24 sites by the Tara Oceans expedition (Karsenti et al. 2011). Their mushroom coral fauna (Scleractinia: Fungiidae) consisted of only six species, one more than previously recorded (Chevalier 1974).

Dense aggregations of large free-living fungiids appeared to be a typical feature of the reef pinnacles in the protected lagoon north of Mangareva Island $\left(23^{\circ} 5.581^{\prime} \mathrm{S} ; 134^{\circ} 59.144^{\prime} \mathrm{W}\right)$. Aggregations on pinnacle tops and upper slopes (3-10 m) were dominated by Danafungia scruposa (Klunzinger, 1879) and Lithophyllon repanda (Dana, 1846) (Fig. 1a). These species were less abundant in deeper assemblages (15-20 m), which predominantly consisted of large Herpolitha limax (Esper, 1797) and Sandalolitha dentata (Quelch, 1884) (Fig. 1b). Lobactis scutaria (Lamarck, 1801) and Pleuractis paumotensis (Stutchbury, 1833) were scarce in both depth zones. It is remarkable that the development of these aggregations was not limited by the low species numbers at Gambier.

The frequent occurrence of attached juveniles as sexually derived recruits (Fig. 1c-f) and the low generation of fragments and buds as asexual propagules in comparison with fungiid aggregations in which these dominant species are less abundant (Hoeksema 2012, references herein) suggest that local sexual reproduction rather than cloning has led to the aggregations in the Gambier Islands, which may indicate a lack of recent disturbance (Gilmour et al. 2006). The species compositions of juveniles and adult mushroom corals indicate that success of sexual reproduction in the assemblages is not necessarily species-dependent and that any effect of interspecific competition by overtopping (Fig. 1a, b) is not apparent.

Acknowledgments We thank the Oceans Consortium, Tara Fonds Paris, $\mathrm{H}$ Bourmaud and the Tara team, P. Mery Haut Commissariat de la République in French Polynesia, and the community of Gambier.

References

Chevalier JP (1974) Aperçu sur les Scléractiniaires des Iles Gambier. Cah Pacif 18:615-627

Gilmour JP, Baird AH, Pratchett MS, Smith LD (2006) The maintenance of populations of the mushroom coral Fungia fungites under different disturbance regimes: sexual versus asexual recruitment. Proc 10th Int Coral Reef Symp:351-358

Hoeksema BW (2012) Distribution patterns of mushroom corals (Scleractinia: Fungiidae) across the Spermonde Shelf, South Sulawesi. Raffles Bull Zool 60:183-212

Karsenti E, Acinas SG, Bork P, Bowler C, De Vargas C, Raes J, Sullivan M, Arendt D, Benzoni F, Claverie J-M, Follows M, Gorsky G, Hingamp P, Iudicone D, Jaillon O, Kandels-Lewis S, Krzic U, Not F, Ogata H, Pesant S, Reynaud EG, Sardet C, Sieracki ME, Speich S, Velayoudon D, Weissenbach J, Wincker P, Tara Oceans Consortium (2011) A holistic approach to marine eco-systems biology. PLoS Biol 9(10):e1001177

B. W. Hoeksema ( $₫)$

Department of Marine Zoology, Naturalis Biodiversity Center, PO Box 9517, 2300 RA Leiden, The Netherlands

e-mail: bert.hoeksema@naturalis.nl

F. Benzoni

Department of Biotechnology and Biosciences, University of Milano-Bicocca, Piazza della Scienza 2, 20126 Milan, Italy

F. Benzoni

Institut de Recherche pour le Développement, UMR227 Coreus2, 101 Promenade Roger Laroque, BP A5, 98848 Nouméa Cedex, New Caledonia

Received: 9 April 2013/Accepted: 10 June 2013/Published online: 21 June 2013

Coral Reefs (2013) 32: 1041

(C) Springer-Verlag Berlin Heidelberg 2013

DOI $10.1007 / \mathrm{s} 00338-013-1054-9$ 